\title{
Enhanced Th17 responses with intestinal dysbiosis in human allergic, inflammatory, and autoimmune diseases
}

\author{
Jun Shimizu and Noboru Suzuki* \\ Department of Immunology and Medicine, St. Marianna University School of Medicine, Japan
}

\begin{abstract}
Researchers have shown that gut microbiota contributed to immune-system maturation and the microbiota compositional changes affected intestinal immune responses. The excessive immune reaction was suggested to spread over the entire blood vessels and induce distant organ damage. We have shown that $\mathrm{T}$ helper 17 (Th17) cells increased and had already been activated in vivo in patients with Behcet's disease (BD). We hypothesized that intestinal dysbiosis (unfavorable changes of microbiota) continuously induced Th17 responses in patients with BD.

A metagenomic analysis of patients with BD and normal individuals revealed that the family Lactobacillaceae, the genera Bifidobacterium and Eggerthella significantly increased in BD patients. The order Clostridiales and the genus Megamonas significantly increased in normal individuals. We suggest that lactate accumulation by increasing Lactobacillus and Bifidobacterium species and low short chain fatty acid concentrations induced by depletion of the order Clostridiales in the intestine may closely relate to the skewed $\mathrm{T}$ cell responses of patients with $\mathrm{BD}$.

In this review, we summarize recent advances in understanding of skewed $\mathrm{T}$ cell function and intestinal dysbiosis in human allergic, inflammatory, and autoimmune diseases.
\end{abstract}

\section{Introduction}

We have promoted personal hygiene and decreased pathogen exposure over the past several decades in Japan. Nonetheless, the ministry of Health, Labor, and Welfare in Japan reported that incidence rates of several allergic and autoimmune diseases have steadily increased. The hygiene hypothesis is based on the idea that frequent pathogen exposure in early life is important to develop adequate systemic immune function. Several researchers reported that children living on farms exposed to higher diversity of environmental microorganisms had lower prevalence of asthma and atopic dermatitis than control children [1].

Children delivered by cesarean section had lower abundance of gut microbes [2] and significantly increased risk of asthma, systemic connective tissue disorders, juvenile arthritis, inflammatory bowel disease, and leukemia compared with those with vaginal delivery [3].

These findings have been obtained by a new sequence based assessment of microbes, namely metagenomics, which is expected to facilitate the development of novel treatments for the immune diseases.

Using the technique, researchers explored whether unfavorable compositional and functional changes of gut microbiota, so called dysbiosis, exist in human allergic, inflammatory, and autoimmune diseases. The dysbiosis of gut microbiota was found in asthma, atopic dermatitis, inflammatory bowel disease, rheumatoid arthritis, psoriasis, multiple sclerosis, and Behcet's disease (BD). Interestingly, hyperactivity of $\mathrm{T}$ helper 17 (Th17) cells were frequently observed in the same disease category as explained below.

We have shown that Th17 cells increased and had already been activated in vivo in patients with $\mathrm{BD}[4,5]$. We demonstrated characteristic compositional changes of BD gut microbiota compared with that of normal individuals using a metagenomic analysis [6]. We suggest that the gut microbe compositional changes may be one type of $\mathrm{BD}$ dysbiosis and have a role in the skewed $\mathrm{T}$ cell responses in patients with BD.

Here, we review recent studies of Th17 cell function and gut microbiota composition in human allergic, inflammatory, and autoimmune diseases, and suggest a possible association between them.

\section{Behcet's disease (BD)}

$\mathrm{BD}$ is a rare systemic inflammatory disorder of unknown etiology. Recurrent attacks of acute inflammation, such as uveitis, aphthous ulcers, genitor ulcers, skin erythema, colitis, vasculitis, and encephalitis characterize BD. Repeated attacks of uveitis can lead to blindness and gastrointestinal, central nervous system, and vascular involvement is associated with poor prognosis [7].

Studies of BD suggest that skewed $\mathrm{T}$ cell function, high prevalence of HLA-B51, and several microbial infection, such as Streptococcus sanguinis and Herpes simplex virus, may play a role in the pathogenesis of BD [7].

Correspondence to: Noboru Suzuki MD, Ph.D, Department of Immunology and Medicine, St. Marianna University School of Medicine, 2-16-1 Sugao, Miyamaeku, Kawasaki, Kanagawa 216-8511, Japan, Tel: +81-44-977-8111 (extn. 3547), Fax: +81-44-976-3315; E-mail: n3suzuki@marianna-u.ac.jp

Key words: intestinal dysbiosis, gut microbiota, metagenomics, Bifidobacterium, Th17 cells, IL23

Received: April 27, 2016; Accepted: June 10, 2016; Published: June 13, 2016 


\section{Enhanced Th17 responses in human allergic, inflammatory, and autoimmune diseases}

Th17 cells produce a number of pro-inflammatory cytokines, including IL17, IL21 and IL22. Th17 cells proliferate in the presence of IL23 and respond to extracellular bacteria and fungi. In mouse experiments, commensal bacterium colonization of segmented filamentous bacteria potently induced Th17 cell differentiation [8]. The bacterium mono-colonization aggravated autoimmune arthritis and experimental autoimmune encephalomyelitis in mouse models [9].

Recently, it was reported that Th17 cells were frequently found in the lesion and peripheral blood of patients in human allergic, inflammatory, and autoimmune diseases, though the numbers of infiltrating cells were limited [4,5,10-20]. The blockades of IL17 and IL23 remarkably ameliorated arthritis and colitis of patients with rheumatoid arthritis and inflammatory bowel disease, respectively [21]. We summarize recent literature demonstrating increased IL17/ IL23 expressions in the lesion of patients with allergic, inflammatory, and autoimmune diseases in Table 1.

Th17 cells are suggested to be highly unstable in the cell fate in vivo and to be converted to IFN $\gamma$ expressing cells, termed unconventional Th1 cells. Conventional and unconventional Th1 cells are distinguished by the presence, in unconventional Th1 cells, of Th17 markers CD161 and CCR6, which are all virtually absent in conventional Th1 cells [11]. The converted T cells express both IFN $\gamma$ and IL17 and are called Th1/Th17 cells [11]. In mouse transplantation models, Th1/Th17 cells expressed both IL12 receptor and IL23 receptor and exhibited stronger pro-inflammatory effects than conventional Th1, and Th17 cells [22]. Researchers frequently observed Th1/Th17 cells in patients who had enhanced IL17/IL23 expressions in the lesion mentioned above (Table 1). It is assumed that Th17 cells are not prevalent in the lesion of human autoimmune diseases because of the cell instability [11].

In BD patients, Th17 cells increased [23,24] and the cells simultaneously and excessively produced Th1- and Th17-related cytokines in peripheral blood and cerebrospinal fluid [25-28].

Our analyses have demonstrated several Th17-related changes in patients with BD. First, we observed high frequencies of Th17 and Th1/ Th17 cells in patients' peripheral blood $[5,6]$. Second, Th17 and Th1/ Th17 cells were found in BD skin specimens of erythema nodosumlike lesion $[5,10]$. Third, freshly separated BD peripheral blood T cells had already been activated and exhibited increased sensitivity to both IL12 and IL23 $[5,6]$. Forth, frequencies of BD Th17 cells were positively correlated with those of IL23 receptor positive cells [6]. Fifth, IL1 $\beta$ and TNF $\alpha$ supplementation, in addition to IL23, significantly increased IL17 production of BD T cells [6].
We hypothesized that $\mathrm{BD}$ mucosal immunity with the gut microbiota continuously provided systemic Th17 responses through overproduction of several pro-inflammatory cytokines.

\section{Intestinal dysbiosis in human allergic, inflammatory, and autoimmune diseases}

In the past decade, there has been an increase in the number of publications which reported intestinal dysbiosis of patients with allergic, inflammatory, and autoimmune diseases.

In general, intestinal microbe composition is influenced by aging. The development of intestinal microbiota is begun with exposure of neonates to the member microbes in the birth canal and the amount of bacteria rapidly increases [29]. After breast-feeding, Bifidobacterium gradually emerges during about 3 days after the delivery and becomes one of the most abundant bacteria within one week. During the weaning period, the bacterial composition resembles that of adult which consists of predominant anaerobic gram-negative rods. Bifidobacterium disappears and Clostridium perfringens markedly increases in number in elderly individuals [29].

Several authors have recognized intestinal dysbiosis was observed in infancy with several allergic diseases, such as asthma [30,31] and atopic dermatitis [32]. The patterns of bacterial compositional alteration varied probably because of the bacterial compositional succession in early life, as mentioned above [33]. The presence of siblings, raising of dogs, growing in the farm, non-pasteurized milk intake, and breast-feeding are suggested to be effective on the frequent exposure to pathogens and reduce the disease risk [33,34]. Gut microbiota composition has been suggested to be associated with respiratory microbiota [34] and to regulate respiratory infection [35,36], and subsequent development of asthma $[37,38]$. These results suggest a new approach to the studies of "the hygiene hypothesis" and the concept of "common mucosal immune system" [34].

In human inflammatory/autoimmune diseases, dysbiosis of patients with inflammatory bowel disease was repeatedly assessed using metagenomics over the past decade [39]. Relative abundance of the phylum Firmicutes significantly decreased and that of the phylum Bacteroides significantly increased in patients with inflammatory bowel disease compared with those in normal individuals [39]. Furthermore, recent studies have demonstrated that intestinal dysbiosis was found in several human inflammatory/autoimmune diseases (Table 1) [40-46].

Table 2 summarizes bacterial compositional alteration patterns shown in patients with diseases displayed in Table 1.

In general, gut bacterial composition and function are suggested to be regulated by two major mechanisms involving gene function, namely

Table 1. Human allergic, inflammatory, and autoimmune diseases characterized by increased IL17/IL23 expressions, Th1/Th17 cell emergence, and intestinal dysbiosis.

\begin{tabular}{|c|c|c|}
\hline Increased IL-17/I123 expressions & Th1/Th17 cell emergence & Intestinal dysbiosis \\
\hline Asthma [11-13] & Asthma $[11-13]^{\mathrm{a}}$ & Asthma $[30,31,33,34]$ \\
\hline Atopic dermatitis $[14]^{\mathrm{b}}$ & Inflammatory bowel disease [15] & Atopic dermatitis $[32,33]$ \\
\hline Inflammatory bowel disease [15] & Multiple sclerosis [16] & Inflammatory bowel disease [39-42] \\
\hline Multiple sclerosis [16] & Psoriasis [18] & Multiple sclerosis [43] \\
\hline Rheumatoid arthritis [17] & Juvenile idiopathic arthritis $[19,20]$ & Rheumatoid arthritis [44] \\
\hline Systemic lupus erythematosus [17] & Behcet's disease $[4,5,25-28]$ & Psoriatic arthritis [45] \\
\hline Psoriasis [18] & & Behcet's disease $[6,46]$ \\
\hline
\end{tabular}

Behcet's disease $[4,5,23,24]$

aL4 and IL17 co-expressing Th2/Th17 cells were observed in patients with asthma. The cells produce robust immune and inflammatory responses compared with conventional Th2 and Th17 cells [11]. ${ }^{\mathrm{b}}$ Asian patients with atopic dermatitis displayed an intermediate phenotype between European American atopic dermatitis patients and European American psoriasis patients [14]. Asian atopic dermatitis patients frequently showed hyperplasia, parakeratosis, and higher Th17 related gene expressions, similar to psoriasis patients. 
the microbe capabilities for utilizing bacterial metabolites, such as short chain fatty acids, and the microbe tolerance to gut environments, such as $\mathrm{pH}$ and bile salt concentrations [47]. Bifidobacterium and Lactobacillus are the most prevalent lactic acid producing and $\mathrm{pH}$ regulating bacteria under the utilization of sugars. Coriobacterium species are lactic acid producing bacteria, too.

Several genera of the order Clostridiales are able to consume lactate and produce short chain fatty acids, such as butyrate and propionate. Short chain fatty acid production of the bacteria was remarkably reduced by lowering the environmental $\mathrm{pH}$ [47]. It was reported that oral administration of short chain fatty acids $[48,49]$ and butyrate-producing bacteria, especially Faecalibacterium prausnitzii in Clostridia [50-52], effectively increased regulatory $\mathrm{T}$ cell differentiation. These results suggest that low $\mathrm{pH}$ and low short chain fatty acid concentrations of the intestinal lumen may induce a vicious cycle of unbalanced $\mathrm{T}$ cell differentiation. In fact, low butyrate concentrations and/or low frequencies of butyrate-producing bacteria in the intestine were observed in patients with inflammatory bowel disease [40-42] and BD [46]. Furthermore, other intestinal immune cell and bacterial metabolites, such as retinoic acid [53] and polysaccharide A [54], were suggested to play a role in $\mathrm{T}$ cell differentiation. Thus, the roles of intestinal dysbiosis in the skewed $\mathrm{T}$ cell differentiation of human diseases are expected to be elucidated with greater accuracy in terms of metagenomic analyses.

\section{Characteristic BD intestinal bacterial compositional alterations}

We hypothesized that dysbiosis of BD gut microbiota continuously provides Th17 type stimulation to peripheral blood lymphocytes. We conducted a metagenomic analysis of gut microbes [6].

The sequencing data showed that the family Lactobacillaceae, the genera Bifidobacterium and Eggerthella increased significantly in patients with $\mathrm{BD}$ (Table 3). The order Clostridiales and the genus Megamonas significantly increased in normal individuals (Table 3). Fecal secretory IgA concentrations increased significantly in
BD patients compared with those in normal individuals [6]. Alpha diversity is defined as the species richness in each individual. Alpha diversity indexes of the bacterial taxa were comparable between $\mathrm{BD}$ patients and normal individuals [6]. Beta diversity is defined as the distance (difference) between two or more groups of plots, where each plot representing a patient/normal subject, calculated from individual species composition data. An exploratory analysis showed a significant difference between $\mathrm{BD}$ patients and normal individuals in beta diversity [6]. We suggest that the compositional changes of gut microbiota observed in $\mathrm{BD}$ patients may have a relationship with the pathogenesis of $\mathrm{BD}$ as one type of dysbiosis. The skewed $\mathrm{T}$ cell differentiation of $\mathrm{BD}$ patients may be caused by dysregulated bacterial metabolites, such as excessive lactate production and short chain fatty acid depletion, as a result of gut microbe compositional changes.

Further, BD dysbiosis shown in our study shared some common features with that of multiple sclerosis (Tables 2 and 3) [43]. From the point of view of intestinal dysbiosis, the two diseases may be classified into the same subcategory of human immune diseases.

\section{Perspectives}

This review article discussed a relationship between Th17 cell differentiation and intestinal dysbiosis in human allergic, inflammatory, and autoimmune diseases. We suggest that peripheral blood Th17 cell function may reflect partly the compositional and functional features of whole commensal bacteria colonizing the intestinal, genital, respiratory, and oral mucosa [55].

We suggest that accurate cut-off values for the assays of Th17 cell frequency and related gene expressions may establish an evaluation method for the status of commensal microbiota. It may be possible for us to define "normal" Th17 cell function and, after comparing the data with metagenomics, to define "healthy" microbiota of normal individuals and "stable" microbiota of patients.

Recently, researchers reported that oral administration of Chinese herbal medicine Qing-Dai was effective in the treatment of patients

Table 2. Intestinal dysbiosis observed in human allergic, inflammatory, and autoimmune disease.

\begin{tabular}{|c|c|c|c|c|}
\hline Human immune diseases & Prevalent bacterial taxa in patients & $\begin{array}{l}\text { Prevalent bacterial taxa in normal } \\
\text { individuals }\end{array}$ & $\alpha$ diversity in patients & $\begin{array}{l}\text { metabolites and gene function in } \\
\text { patients }\end{array}$ \\
\hline Asthma $[30,31,33,34]$ & Clostridia, Enterococci & Veillonella, Faecalibacterium & Decreased & Decreased acetate concentration \\
\hline Atopic dermatitis $[32,33]$ & Clostridium & Bacteroides & Decreased & \\
\hline Inflammatory bowel disease [39-42] & Gammaproteobacteria & $\begin{array}{l}\text { Clostridia, Ruminococcaceae, } \\
\text { Bifidobacterium, Lactobacillus }\end{array}$ & Decreased & Decreased butyrate concentration \\
\hline Multiple sclerosis [43] & Eggerthella & Megamonas, Prevottella & Comparable & \\
\hline Rheumatoid arthritis [44] & Prevottella & Bacteroides & Decreased & $\begin{array}{l}\text { Low abundance of vitamin } \\
\text { metabolism gene }\end{array}$ \\
\hline Psoriatic arthritis [45] & None & Clostridia & Decreased & $\begin{array}{l}\text { Decreased heptanoate and } \\
\text { hexanoate concentration }\end{array}$ \\
\hline $\mathrm{BD}[46]$ & Bacteroidales & Roseburia, Subdoligranulum & Decreased & Decreased butyrate concentration \\
\hline
\end{tabular}

Table 3. BD intestinal dysbiosis observed in our study [6].

\begin{tabular}{|l|l|l|l|l|}
\hline Prevalent bacterial taxa in BD patients & \multicolumn{3}{l|}{ Prevalent bacterial taxa in normal individuals } \\
\hline Order & Family & Genus & Order & Family \\
\hline Bifidobacteriales & Bifidobacteriaceae & Bifidobacterium & Clostridiales & Veillonellaceae \\
\hline Coriobacteriales & Coriobacteriaceae & Eggerthella & & Paraprevotellaceae \\
\hline Bacillales & Peptostreptococcaceae & Filifactor & & Prevotellaceae \\
\hline CW040 & Lactobacillaceae & Coprobacillus & & \\
\hline & & Enterobacter & & \\
\hline & & Atopobium & & \\
\hline & & Oribacteium & & \\
\hline
\end{tabular}


with ulcerative colitis [56,57]. They suggest that Qing-Dai reduces disease activity possibly by inhibiting Th17 cell differentiation through aryl hydrocarbon receptor (AhR). AhR is a member of the basic helixloop-helix superfamily of transcription factors and is reported to be activated by ligands, including Qing-Dai [56,58]. The ubiquitous and highly conserved protein AhR recognizes a lot of herbal extracts and modulates the expression of a set of genes [59]. Intestinal microbes are able to produce AhR ligands, such as indole-3-aldehyde (3-IAId) and indole 3-acetaldehyde, both of which are intermediates in tryptophan metabolism [56,59]. AhR and the ligand interactions are thought to be essential for the adequate maintenance of the intestine [59]. Daily food intake plays a role in the metabolite interaction including tryptophan [59].

Lactobacilli were reported to become abundant in tryptophan-rich environment of gastrointestinal tract and the bacteria generated 3-IAId [60]. The AhR ligand activated innate lymphocytes to produce IL22 and contributed to mucosal resistance against Candida albicance through the lymphocyte activation $[60,61]$. The IL22 expressing lymphocytes regulated colonization of segmented filamentous bacteria, the Th17 cell inducing gut commensal bacteria, too. The inhibitory effect of IL22 expressing cells was suggested to indicate a negative feedback loop for controlling excessive activation of Th17 cells [61]. Protective effects of 3-IAId on the local immunity was found in the vaginal mucosa [60].

$10 \%$ of patients treated with Qing-Die developed mild liver dysfunction [56]. These data support that probiotics and prebiotics, even food ingredients, have variable effects on the intestinal immune system and we need to clarify the relationship among them.

\section{Acknowledgements}

The authors would like to thank our laboratory Professor K. Takai for useful discussions.

\section{References}

1. Ege MJ, Mayer M, Normand AC, Genuneit J, Cookson WO, et al. (2011) Exposure to environmental microorganisms and childhood asthma. N Engl J Med 364: 701-709. [Crossref]

2. Dominguez-Bello MG, De Jesus-Laboy KM, Shen N, Cox LM, et al. (2016) Partial restoration of the microbiota of cesarean-born infants via vaginal microbial transfer. Nat Med 22: 250-253. [Crossref]

3. Sevelsted A, Stokholm J, Bønnelykke K, Bisgaard H (2015) Cesarean section and chronic immune disorders. Pediatrics 135: e92-98. [Crossref]

4. Shimizu J, Takai K, Fujiwara N, Arimitsu N, Ueda Y, et al. (2012) Excessive CD4+ T cells co-expressing interleukin-17 and interferon- $\gamma$ in patients with Behçet's disease. Clin Exp Immunol168: 68-74. [Crossref]

5. Shimizu J, Takai K, Takada E, Fujiwara N, Arimitsu N, et al. (2015) Possible association of proinflammatory cytokines including IL1 $\beta$ and TNF $\alpha$ with enhanced Th17 cell differentiation in patients with Behcet's disease. Clin Rheumatol. [Crossref]

6. Shimizu J, Kubota T, Takada E, Takai K, Fujiwara N, et al. (2016) Bifidobacteria Abundance-Featured Gut Microbiota Compositional Change in Patients with Behcet's Disease. PLoS One 11: e0153746. [Crossref]

7. Sakane T, Takeno M, Suzuki N, Inaba G (1999) Behçet's disease. N Engl J Med 341: 1284-1291. [Crossref]

8. Furusawa Y, Obata Y, Hase K (2015) Commensal microbiota regulates T cell fate decision in the gut. Semin Immunopathol 37: 17-25. [Crossref]

9. Kayama H, Takeda K (2016) Functions of innate immune cells and commensal bacteria in gut homeostasis. J Biochem 159: 141-149. [Crossref]

10. Shimizu J, Kaneko F, Suzuki N (2013) Skewed Helper T-Cell Responses to IL-12 Family Cytokines Produced by Antigen-Presenting Cells and the Genetic Background in Behcet's Disease. Genet Res Int 2013: 363859.

11. Cosmi L, Liotta F, Maggi E, Romagnani S, Annunziato F (2014) Th17 and non-classic
Th1 cells in chronic inflammatory disorders: two sides of the same coin. Int Arch Allergy Immunol 164: 171-177. [Crossref]

12. Cosmi L, Maggi L, Santarlasci V, Capone M, Cardilicchia E, et al. (2010) Identification of a novel subset of human circulating memory CD4 $(+) \mathrm{T}$ cells that produce both IL17A and IL-4. J Allergy ClinImmunol 125: 222-230. [Crossref]

13. Wang YH, Voo KS, Liu B, Chen CY, Uygungil B, et al. (2010) A novel subset of CD4(+) $\mathrm{T}(\mathrm{H}) 2$ memory/effector cells that produce inflammatory IL-17 cytokine and promote the exacerbation of chronic allergic asthma. J Exp Med 207: 2479-2491. [Crossref]

14. Noda S, Suárez-Fariñas M, Ungar B, Kim SJ, de Guzman Strong C, et al. (2015) The Asian atopic dermatitis phenotype combines features of atopic dermatitis and psoriasis with increased TH17 polarization. J Allergy Clin Immunol 136: 1254-1264. [Crossref]

15. Annunziato F, Cosmi L, Santarlasci V, Maggi L, Liotta F, et al. (2007) Phenotypic and functional features of human Th17 cells. J Exp Med 204: 1849-1861. [Crossref]

16. Kebir H, Ifergan I, Alvarez JI, Bernard M, Poirier J, et al. (2009) Preferential recruitment of interferon-gamma-expressing TH17 cells in multiple sclerosis. Ann Neurol 66: 390-402. [Crossref]

17. Sherlock JP, Taylor PC, Buckley CD (2015) The biology of IL-23 and IL-17 and their therapeutic targeting in rheumatic diseases. Curr Opin Rheumatol 27: 71-75. [Crossref]

18. Hänsel A, Günther C, Ingwersen J, Starke J, Schmitz M, et al. (2011) Human slan (6-sulfo LacNAc) dendritic cells are inflammatory dermal dendritic cells in psoriasis and drive strong TH17/TH1 T-cell responses. J Allergy Clin Immunol 127: 787-794. [Crossref]

19. Nistala K, Adams S, Cambrook H, Ursu S, Olivito B, et al. (2010) Th17 plasticity in human autoimmune arthritis is driven by the inflammatory environment. Proc Natl Acad Sci U S A 107: 14751-14756. [Crossref]

20. Cosmi L, Cimaz R, Maggi L, Santarlasci V, Capone M, et al. (2011) Evidence of the transient nature of the Th17 phenotype of CD4+CD161+ T cells in the synovial fluid of patients with juvenile idiopathic arthritis. Arthritis Rheumtol 63: 2504-2515. [Crossref]

21. Yang J, Sundrud MS, Skepner J, Yamagata T (2014) Targeting Th17 cells in autoimmune diseases. Trends Pharmacol Sci 35: 493-500. [Crossref]

22. Bending D, De la Peña H, Veldhoen M, Phillips JM, Uyttenhove C, et al. (2009) Highly purified Th17 cells from BDC2.5NOD mice convert into Th1-like cells in NOD/SCID recipient mice. J Clin Invest 119: 565-572. [Crossref]

23. Chi W, Zhu X, Yang P, Liu X, Lin X, et al. (2008) Upregulated IL-23 and IL-17 in Behçet patients with active uveitis. Invest Ophthalmol Vis Sci 49: 3058-3064. [Crossref]

24. Hamzaoui K, Bouali E, Ghorbel I, Khanfir M, Houman H, et al. (2011) Expression of Th-17 and RORÎt mRNA in BehÃßet's Disease. Med Sci Monit 17: CR227-234. [Crossref]

25. Geri G, Terrier B, Rosenzwajg M, Wechsler B, Touzot M, et al. (2011) Critical role of IL-21 in modulating TH17 and regulatory T cells in Behçet disease. J Allergy Clin Immunol 128: 655-664. [Crossref]

26. Hamzaoui K, BorhaniHaghighi A, Ghorbel IB, Houman H (2011) RORC and Foxp3 axis in cerebrospinal fluid of patients with neuro-Behçet's disease. J Neuroimmunol 233: 249-253. [Crossref]

27. Chi W, Yang P, Zhu X, Wang Y, Chen L, et al. (2010) Production of interleukin-17 in Behcet's disease is inhibited by cyclosporin A. Mol Vis 16: 880-886. [Crossref]

28. Na SY, Park MJ, Park S, Lee ES (2013) Up-regulation of Th17 and related cytokines in Behçet's disease corresponding to disease activity. Clin Exp Rheumatol 31: 32-40. [Crossref]

29. Mitsuoka T (2014) Establishment of intestinal bacteriology. BiosciMicrobiota Food Health 33: 99-116. [Crossref]

30. Arrieta MC, Stiemsma LT, Dimitriu PA, Thorson L, Russell S, et al. (2015) Early infancy microbial and metabolic alterations affect risk of childhood asthma. Sci Transl Med 7: 307ra152. [Crossref]

31. van Nimwegen FA, Penders J, Stobberingh EE, Postma DS, Koppelman GH, et al. (2011) Mode and place of delivery, gastrointestinal microbiota, and their influence on asthma and atopy. J Allergy Clin Immunol 128: 948-955. [Crossref]

32. Nylund L, Satokari R, Nikkilä J, Rajilic-Stojanovic M, Kalliomäki M, et al. (2013) Microarray analysis reveals marked intestinal microbiota aberrancy in infants having eczema compared to healthy children in at-risk for atopic disease. BMC Microbiol 13: 12. [Crossref]

33. West CE (2014) Gut microbiota and allergic disease: new findings. Curr Opin Clin Nutr Metab Care 17: 261-266. [Crossref] 
34. Huang YJ, Boushey HA (2015) Themicrobiome in asthma. J Allergy Clin Immunol 135: 25-30. [Crossref]

35. Ichinohe T, Pang IK, Kumamoto Y, Peaper DR, Ho JH, et al. (2011) Microbiota regulates immune defense against respiratory tract influenza A virus infection. Proc Natl Acad Sci U S A 108: 5354-5359. [Crossref]

36. Yasui H, Kiyoshima J, Hori T (2004) Reduction of influenza virus titer and protection against influenza virus infection in infant mice fed Lactobacillus caseiShirota. Clin Diagn Lab Immunol 11: 675-679. [Crossref]

37. Bisgaard H, Hermansen MN, Buchvald F, Loland L, Halkjaer LB, et al. (2007) Childhood asthma after bacterial colonization of the airway in neonates. N Engl J Med 357: 1487-1495. [Crossref]

38. Jackson DJ, Gangnon RE, Evans MD, Roberg KA, Anderson EL, et al. (2008) Wheezing rhinovirus illnesses in early life predict asthma development in high-risk children. Am J Respir Crit Care Med 178: 667-672. [Crossref]

39. Kostic AD, Xavier RJ, Gevers D (2014) Themicrobiome in inflammatory bowel disease: current status and the future ahead. Gastroenterology 146: 1489-1499. [Crossref]

40. Erickson AR, Cantarel BL, Lamendella R, Darzi Y, Mongodin EF, et al. (2012) Integrated metagenomics/metaproteomics reveals human host-microbiota signatures of Crohn's disease. PLoS One 7: e49138. [Crossref]

41. Morgan XC, Tickle TL, Sokol H, Gevers D, Devaney KL, et al. (2012) Dysfunction of the intestinal microbiome in inflammatory bowel disease and treatment. Genome Biol 13: R79. [Crossref]

42. Takahashi K, Nishida A, Fujimoto T, Fujii M, Shioya M, et al. (2016) Reduced Abundance of Butyrate-Producing Bacteria Species in the Fecal Microbial Community in Crohn's Disease. Digestion 93: 59-65. [Crossref]

43. Miyake S, Kim S, Suda W, Oshima K, Nakamura M, et al. (2015) Dysbiosis in the Gut Microbiota of Patients with Multiple Sclerosis, with a Striking Depletion of Species Belonging to Clostridia XIVa and IV Clusters. PLoS One 10: e0137429. [Crossref]

44. Scher JU, Sczesnak A, Longman RS, Segata N, Ubeda C, et al. (2013) Expansion of intestinal Prevotellacopri correlates with enhanced susceptibility to arthritis. Elife 2: e01202. [Crossref]

45. Scher JU, Ubeda C, Artacho A, Attur M, Isaac S, et al. (2015) Decreased bacterial diversity characterizes the altered gut microbiota in patients with psoriatic arthritis, resembling dysbiosis in inflammatory bowel disease. Arthritis Rheumatol 67: 128-139. [Crossref]

46. Consolandi C, Turroni S, Emmi G, Severgnini M, Fiori J, et al. (2015) Behçet's syndrome patients exhibit specific microbiome signature. Autoimmun Rev 14: 269276. [Crossref]

47. Flint HJ, Duncan SH, Scott KP, Louis P (2015) Links between diet, gut microbiota composition and gut metabolism. Proc Nutr Soc 74: 13-22. [Crossref]
48. Smith PM, Howitt MR, Panikov N, Michaud M, Gallini CA, et al. (2013) The microbial metabolites, short-chain fatty acids, regulate colonic Treg cell homeostasis. Science 341: 569-573. [Crossref]

49. Arpaia N, Campbell C, Fan X, Dikiy S, van der Veeken J, et al. (2013) Metabolites produced by commensal bacteria promote peripheral regulatory T-cell generation. Nature 504: 451-455. [Crossref]

50. Atarashi K, Tanoue T, Oshima K, Suda W, Nagano Y, et al. (2013) Treg induction by a rationally selected mixture of Clostridia strains from the human microbiota. Nature 500: 232-236. [Crossref]

51. Tanaka S, Yamamoto K, Yamada K, Furuya K, Uyeno Y (2016) Relationship of Enhanced Butyrate Production by Colonic Butyrate-Producing Bacteria to Immunomodulatory Effects in Normal Mice Fed an Insoluble Fraction of Brassica rapa L. Appl Environ Microbiol 82: 2693-2699.

52. Qiu X, Zhang M, Yang X, Hong N, Yu C (2013) Faecalibacteriumprausnitziiupregulates regulatory $\mathrm{T}$ cells and anti-inflammatory cytokines in treating TNBS-induced colitis. $J$ Crohns Colitis 7: e558-568. [Crossref]

53. Mucida D, Park Y, Kim G, Turovskaya O, Scott I, et al. (2007) Reciprocal TH17 and regulatory $\mathrm{T}$ cell differentiation mediated by retinoic acid. Science 317: 256-260. [Crossref]

54. Round JL, Mazmanian SK (2010) Inducible Foxp3+ regulatory T-cell development by a commensal bacterium of the intestinal microbiota. Proc Natl Acad Sci U S A 107: 12204-12209. [Crossref]

55. van der Meulen TA, Harmsen HJ, Bootsma H, Spijkervet FK, Kroese FG, et al. (2016) The microbiome systemic diseases connection. Oral Dis. [Crossref]

56. Sugimoto S, Naganuma M, Kiyohara H, Arai M, Ono K, et al. (2016) Clinical Efficacy and Safety of Oral Qing-Dai in Patients with Ulcerative Colitis: A Single-Center OpenLabel Prospective Study. Digestion 93: 193-201. [Crossref]

57. Suzuki H, Kaneko T, Mizokami Y, Narasaka T, Endo S, et al. (2013) Therapeutic efficacy of the Qing Dai in patients with intractable ulcerative colitis. World $J$ Gastroenterol 19: 2718-2722. [Crossref]

58. Bersten DC, Sullivan AE, Peet DJ, Whitelaw ML (2013) bHLH-PAS proteins in cancer Nat Rev Cancer 13: 827-841. [Crossref]

59. Zelante T, Iannitti RG, Fallarino F, Gargaro M, De Luca A, et al. (2014) Tryptophan Feeding of the IDO1-AhR Axis in Host-Microbial Symbiosis. Front Immunol 5: 640. [Crossref]

60. Zelante T, Iannitti RG, Cunha C, De Luca A, Giovannini G, et al. (2013) Tryptophan catabolites from microbiota engage aryl hydrocarbon receptor and balance mucosal reactivity via interleukin-22. Immunity 39: 372-385. [Crossref]

61. Qiu J, Guo X, Chen ZM, He L, Sonnenberg GF, et al. (2013) Group 3 innate lymphoid cells inhibit T-cell-mediated intestinal inflammation through aryl hydrocarbon receptor signaling and regulation of microflora. Immunity 39: 386-399. [Crossref]

Copyright: $\odot 2016$ Shimizu J. This is an open-access article distributed under the terms of the Creative Commons Attribution License, which permits unrestricted use, distribution, and reproduction in any medium, provided the original author and source are credited. 